\title{
Toward a Psycholinguistic Model of Affective Variables in EFL Contexts
}

\author{
Mohammad Ali Heidari-Shahreza \\ Department of English, Faculty of Humanities, Shahreza Branch, Islamic Azad University, \\ Shahreza, Isfahan, Iran \\ E-mail address: maheidari.sh@gmail.com
}

\begin{abstract}
The present study initially aimed at exploring the realm of affective variables such as motivation, anxiety and inhibition by reviewing the prevailing models and taxonomies used to account for such variables in the relevant literature. In so doing, three common approaches to the study of affective vriables, that is, (meta) cognitive approach, socio-cultural approach and the (more recent) contextual approach were elaborated on. Secondly, as the primary purpose of the study, a trichotomous model of affective variables within a contextual approach was put forward. Based on this tentative model, three macro components of a contextual approach to affective variables were identified as a) learners' objectives; b) learning environment and c) learners' emotions and feelings. A number of components were also highlighted at micro level under the three categories of objective-oriented, environmentoriented and feeling-oriented taxonomy of this model. Finally, these components were briefly discussed and their pedagogical implications for language teachers were drawn upon.
\end{abstract}

Keywords: Affective variables; Learners' objectives; learning environment; EFL context

\section{INTRODUCTION}

In recent years, more emphasis has been given to EFL learners' psychological or affective variables such as attitude, motivation, anxiety and beliefs (Abedini, Rahimi, \& Zare-ee, 2011). This emphasis has resulted from the important role such variables play in language learning and teaching in general and EFL learners' success (as a language learner) in particular. As concluded long ago by Savignon (1983), affective variables have a stronger impact on learners' success in acquiring a second or foreign language than those cognitive or educational factors such as intelligence, aptitude, teaching methods and techniques (cited in Kennedy, Nelson, Odell, and Austin, 2000, p. 279). Moreover, it consciously (or subconsciously) affects the learners' approaches to the task of learning a foreign language (Abdolahzadeh \& Rajaee Nia, 2014). As White (1999) points out, affective variables particularly learners' beliefs are formed before and while they experience a new language and can guide learners' expectations.

A popular framework to investigate affective variables for more than two decades has been Horwitz's (1987) Beliefs About Language Learning Inventory (BALLI). Based on this inventory, the relation between learners' affective variables especially their beliefs and language-related issues such as proficiency, culture, gender and strategy use have been 
examined (Rieger, 2009). Another framework is Byram's (2004) Resultative and Motivational Hypothesis which mainly focuses on learners' attitudes about language learning.

Gardner's (1985) Socio-Educational Model and Dörnyei and Ottó's (1998) Process Model of L2 Motivation are also developed over these years to account for affective variables such as motivation and social interaction within the realm of language learning and teaching. As the mentioned models and frameworks suggest, research into affective variables have been under the influence of research in cognitive psychology. Early studies on such variables mainly employed cognitive approaches as research orientations. Based on such approach, affective factors such as beliefs were regarded as an internal autonomous property of the mind and were explored to discern how they were linked to learners' success and level of attainment. Affective variables have also been investigated from a sociocultural viewpoint. Sociocultural approaches often see beliefs as a by-product of social transactions (Gabillon, 2002). A mixed approach is also perceivable based on which affective variables are formed as a result of learners' individual mental processes and social context of such variables.

Most recently, some scholars tend to view affective variables as "context-sensitive, thus dynamic and lively" (Kaypak \& Ortaçtepe, 2014). As Wenden (1999) points out, "conceptions and beliefs about learning should not be viewed independently of context but rather as functional in a given context of learning" (p. 438). In this regard, Barcelos (2003) also proposes three approaches to study affective variables: the normative approach, the metacognitive approach and the contextual approach.

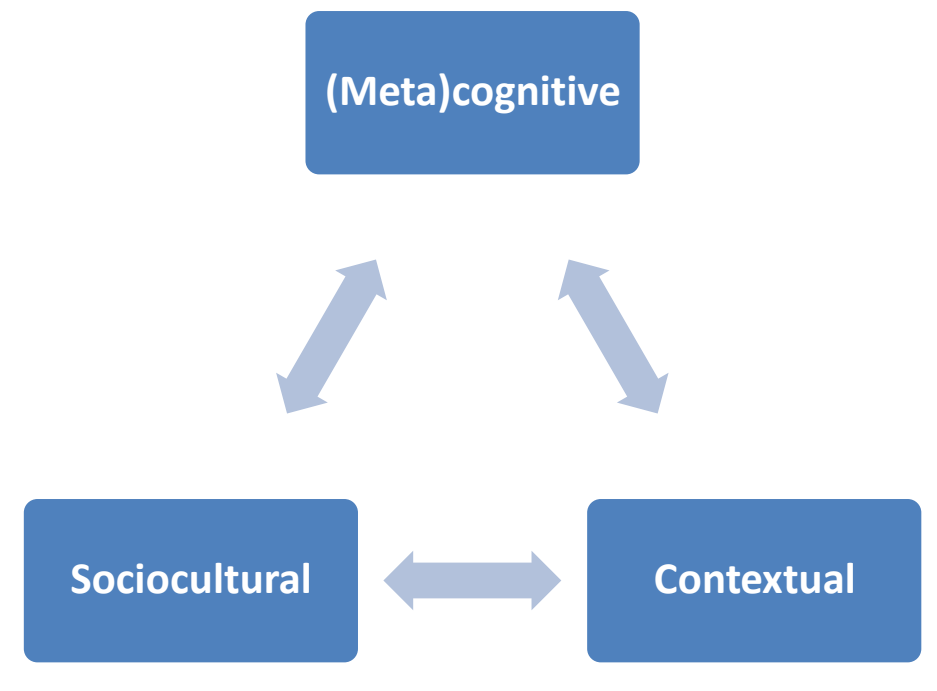

Figure 1. Three approaches to affective variables.

In sum, as Figure 1 shows, the literature on affective variables suggests three approaches to account for these factors in language learning and teaching: (Mata)cognitive approach which views affective variables a part and a product of learners' cognition and cognitive processes; sociocultural approach based on which learners' affects are formed and altered through social transactions and the more recent approach, contextual approach postulates that the context of learning and/or teaching significantly contributes to affective variables such as motivation, anxiety, etc. 


\section{PRPOSED MODEL OF AFFECTIVE VARIABLES}

Within the contextual approach, the researcher identified three contributing components: a) learners' objectives; b) learning environment and c) learners' emotions and feelings (see Figure 2). The first component refers to the learning goals and purposes learners aim at. These learning goals often cover a vast area of learners' current and future lives such as their job, their academic advancement and their interaction with people from other cultures. In general, following Heidari-Shahreza (2014), learners' objectives can be classified into five categories of a) occupational; b) communicative; c) academic; d) cultural and recreational.

The second component, learning environment, mainly refers to language classrooms and laboratories where learning takes place. It is, however, worth noting that in recent years thanks to advances in information technology, learning environment has an extended meaning covering virtual learning locations such as websites and weblogs. The third component refers to learners' emotions and feelings as psychological states.

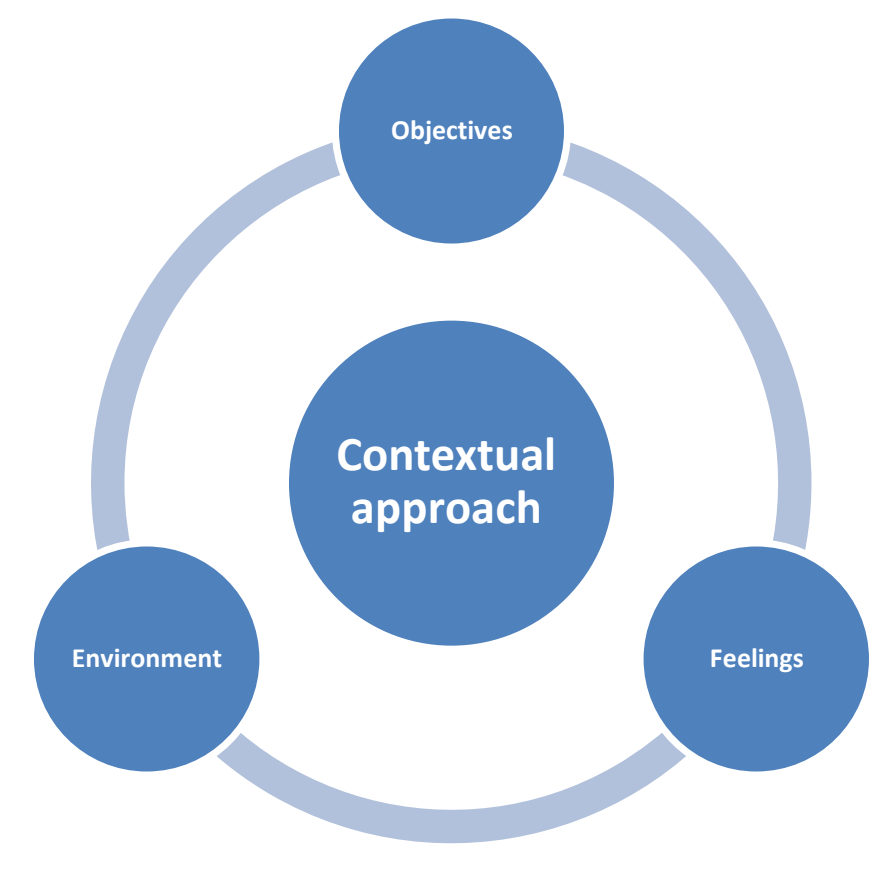

Figure 2. A trichotomous model of contextual approach.

Within this proposed model of contextual approach, each macro-component also incorporates a number of micro-components. In the following, these micro-components and their interplay with other macro- and micro-components are elaborated on (see Figure 3): 


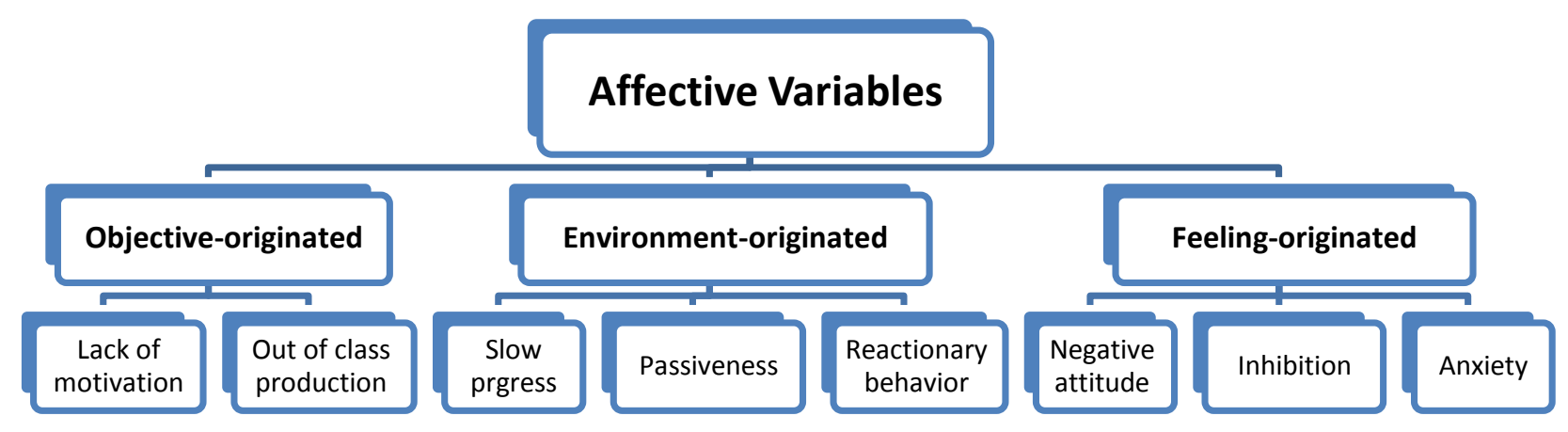

Figure 3. The proposed model of contextual approach at micro level.

\section{1. Objective-originated Affective Variables}

While providing an inclusive list is not feasible, two important factors which based on the relevant literature, most often contribute to this category of affective variables are discussed:

\section{1. 1. Lack of motivation}

Motivation is one of the most important factors which remarkably influence language learning. "It is a state of cognitive and emotional arousal which leads to a conscious decision to act and which gives rise to a period of sustained intellectual and/or physical effort in order to attain a previously set goal (or goals.)"(Williams \& Burden, 1997:120)

Lack of motivation is a substantial affective filter which hinders the process of learning and lends itself to many other problems as well. It may originate from different sources. According to the three-stage model of motivation proposed by Williams and Burden (1997), students' language objectives are the initiating stage of motivation which without fulfilling this stage, the other stages cannot be even inaugurated. Many English teachers especially EFL ones complain about the students, who do not complete their homework, are passive in class and show no interest in language learning at all. In spite of the fact that the cause of these problems may be various, in most cases the lack of motivation plays the major role. It is more defendable at the point that those students are active and interested in other courses (see also Csizér \& Dörnyei, 2005).

\section{1. 2. Out-of-class production}

A major problem observed with many English students is that they are not eager in putting into practice what they have learned in class. One may think if an appropriate method is practiced in class and students are equipped with different language competences (e.g., linguistic, communicative, strategic, etc), they eagerly use their language abilities in real situations. It is, however, the case that many English senior students do not breathe even one English word out of the class unless they are obliged to (Heidari-Shahreza, 2014b). While they certainly have the ability to use English and their English teachers and the kind of syllabus used in the course urge them to do so, there is little (if any) out of class production. The main cause of this so-called language infertility is that they do not find any considerable link between what they have learned and what they have aspired to learn. Simply put, their language objectives were not even partially fulfilled. 


\section{2. Environment-originated Affective Variables}

In the context of the proposed model, 'environment' is used to signify both language classroom as the place where the main part of learning takes place and English teachers whom their behavior (especially its interpersonal aspect) is very important for a successful learning. As Williams and Burden (1997) point out the importance of appropriate learning environment should not be overlooked. Moreover, language classroom and the personal interactions which occur in it have a profound influence on language learning. Therefore, environment-originated variables refer to those affective barriers which are aroused due to the inappropriate classroom settings or the unqualified English teachers. Here are some environment-originated factors:

\section{2. 1. Students' slow progress}

One of the most important problems in language teaching is the slow progress of students (Heidari-Shahreza, 2014a). Many English teachers complain that their students do not acquire learning materials at a desirable rate. Although this problem may root from different sources, taking into consideration the overall success of students in schooling years and their good cognitive abilities, we are convinced to put the blame mostly on learning environment deficiencies. In fact, many language classrooms especially the ones in countries with less developed educational systems are not provided with any kind of audiovisual aids such as flash cards, pictures, maps, videos etc. To make the problem more detrimental, is the procedure which some English teachers take; that is a mechanical presentation of some isolated boring materials (Williams \& Burden, 1997).

\section{2. 2. Students' passiveness}

Another major complaint of many English teachers is the passiveness of the students. That is, they usually sit idle and do not take part in activities. The most influential reason for this problem is the learning environment. If the environment is attractive and motivating enough, even the most passive learner is also somehow inclined (even if not totally persuaded) to participate in learning activities and involvements (Csizér \& Dörnyei, 2005). However, the bitter fact is that in most cases language classrooms is dull and disappointing. English students usually enter language classrooms with an image in their minds which lies on the supposition that their classrooms are interesting, lively and in a word somewhere like the real situation in which they have seen or (at least) presupposed native speakers have communication with one another; This image is often distorted at the moment on which they enter the classrooms and look around. That is why they usually sit idle. They feel as if they have entered the wrong place.

\section{2. 3. Students' reactionary behavior}

Students' reactionary behavior refer to the opposing behavior of some students to learning activities and more noticeably to the instructional aims which English teachers try to put into practice. It is an old but untold problem of many English teachers; they feel as if their students are not only unwilling to learning but also they try to frustrate their instructional objectives. The learning environment (including English teachers) may put the students in a situation in which they feel entrapped. In a situation such as this, students may consciously or unconsciously try to negatively react to what is presented in class as an opposing (or relieving) agent to what they feel an oppressive burden on their shoulders (see also Abedini, Rahimi, \& Zare-ee, 2011). 


\section{3. Feeling-originated Affective Variables}

Feeling-originated affective variables refer to the problems which originate from students' feelings or more technically affects. "Affect refers to emotion or feeling. The affective domain is the emotional side of human behavior, and it may be juxtaposed to the cognitive side. The development of affective states or feelings involves variety of personality factors, feelings both about ourselves and about others with whom we come into contact" (Douglas Brown, 2000). Feeling-originated problems or affective filters cover a wide variety of hurdles which impede in language learning. Despite the fact that these problems are of primary importance and should be taken into account seriously, they are devoted very little attention and are considered only when they come to the fore. Here are some important feelingoriginated problems.

\section{3. 1. Students' negative attitude}

Attitude represents an individual's like/dislike for an item or a certain way of reaction or consideration to/of an issue. English students may have positive, negative, neutral or mixed attitudes about language and the issues related to it. Students' negative attitude is a detrimental problem which is often overlooked (Kaypak \& Ortaçtepe, 2014). Unfortunately, many English teachers are ignorant of its harm and they usually take this problem into consideration at the point that it has already affected their teaching conspicuously. Students' negative attitude may be triggered from various sources However, in many cases it is evolved from some kind of feeling which has been formed or injected in students; mind due to a negative stimulus. Negative attitude of students should be changed into a positive one (or at least, it should be balanced to a neutral one) before learning process actually begins.

\section{3. 2. Inhibition}

Inhibition is defined as a conscious or subconscious control of a process or behavior, especially of impulses or feelings. Inhibition, however, in language learning has been proved as a detrimental problem (Douglas Brown, 2000). It may be disguised in many forms. It often sidetracks the teachers to some false incentives which usually have nothing to do with inhibition itself. Imagine a situation in which the inability of the student to answer a question is regarded as an indication of his lack of knowledge while the real reason is inhibition. This problem is usually originated from students' feelings. There, in English students' minds some kinds of hindering feelings are working which make them unwilling to express themselves or demonstrate their abilities. "Language teaching approaches in the last three decades have been characterized by the creation of context in which students are made to, to orally try out hypotheses, and in so doing to break down some of the barriers that often make students reluctant to try out their new language" (Douglas Brown, 2000). It is up to English teachers to detect and remove these feelings and help the students feel at home.

\subsubsection{Anxiety}

Psychologically speaking, Anxiety is an unpleasant state of emotional and physiological arousal that people experience in situations that they perceive as dangerous, threatening or humiliating to their well-being. "Although we all know what anxiety is and we all have experienced feelings of anxiousness, anxiety is still not easy to define in a simple sentence. It is associated with feelings of uneasiness, frustration, self-doubt, apprehension, or worry" (Douglas Brown, 2000). Anxiety is a problem which is very common in language classes. 
Almost all students experience some kind of anxiety during their learning years. Although it is often considered a problem, it should be noted that a certain amount of anxiety is helpful. What makes anxiety a negative element in learning is actually the excess amount of anxiety (or technically debilitative anxiety) which hinders the process of learning. David Shinji Kondo and Yang Ying-Ling (2004) having studied the anxiety in the students of English in Japan, suggest 70 basic tactics to cope with language anxiety cohered into five strategy categories: Preparation (e.g. studying hard), Relaxation (e.g. taking a deep breath), Positive Thinking (e.g. trying to enjoy the tension), Peer seeking (e.g. asking other students if they understand the class), and Resignation (e.g. giving up).

\section{CONCLUSIONS}

As we discussed earlier in this paper, one of the most important issues influencing the overall success of students and a very likely source of their language problems is language objectives. In other words, in a considerable number of cases, if students' language objectives are not desirably fulfilled by the curriculum or if it is not, at least, in parallel with their objectives, quite a number of problems may arise. In addition, as Heidari-Shahreza (2014) concludes, the majority of English students have a kind of occupational, communicative, cultural objectives therefore, it seems quite reasonable to suggest that the curriculum should pivot around the instructional materials which are conducive to the fulfillment of students' language objectives. To do so, adding LSP (Language for Specific Purposes) instructional materials especially EOP (English for Occupational Purposes) ones can be useful.

Furthermore, the cultural aspect of English language should be injected to the curriculum. Unfortunately, at present, there is little opportunity for the students to learn about English culture in many EFL contexts. Moreover, the relevant literature suggests that an important factor influencing students' success in language learning is familiarity with the second language culture (Douglas Brown, 2000). In addition, there is general consensus that language is so interrelated to culture that using language successfully without having the essential familiarity with its culture is practically foredoomed to misunderstanding and incomprehensibility. Finally, since many English students would like to communicate with English speakers, a kind of communicative learning setting should be set up. Communicative activities can be very helpful to reinforce students' communicative competence.

Another area of concern in this paper was the learning environment and the problems which may arouse from it. The learning environment (including English teachers) should be interesting, purposeful and productive. It is not a place to merely hold the students but also a place to put up the students' learning foundations. Therefore maximum effort should be made to build an environment which really resembles the real context of the language and enables the students to enhance their language skills and abilities. Moreover, as Heidari-Shahreza (2014) points out many English teachers fail to attract, motivate and provide students with interesting useful materials and activities. To remove these shortcomings it is strongly recommended that English teachers a) behave friendly and sociably, b) give the students a clear attracting outline of English courses and the benefits they can take from them, c) be creative and take the initiative to use various useful activities d) be aware of learning variables such as age, gender etc. and finally e) understand and appreciate students' different learning strategies.

Since many English teachers, run short of activities to cover the learning time, some hints are presented to fill the class time with interesting activities: a) learning activities (or rather tasks) can be very simple but still useful, b) a part of teacher's art of teaching is to use the very 
simple objects available to him/her to involve students in interesting activities, c) there are many funny enjoyable games, "twenty questions" for example, which can be purposefully used in language classrooms, d) general issues such as money, house etc. can be a very good source for many activities especially problem-solving ones or discussions and finally e) internet can be used for a wide range of activities ( and assignments.)

The third issue discussed in this paper was students' feelings and the problems related to them. First of all, it was warned that many problems of this kind are not taken into account seriously until too late a point when these problems have come to the fore. What is more, they are disguised in many various forms. Therefore, many English teachers fail to detect the real, detrimental affective problem (or rather, filter) negatively influencing students' performance. To obviate these problems, at the first stage, an awareness of different psychological problems involving in language learning is substantially essential for English teachers. Secondly, the learning environment should be set up in a way that all English students feel free and secure. Finally a regular intermittent evaluation of students' feelings (done informally by teachers or formally by educational authorities can be very helpful to detect and subsequently remove these problems.

\section{References}

[1] Abdolahzadeh E., RajaeeNia M., Procedia - Social and Behavioral Sciences 98 (2014 ) 22- 28 .

[2] Abedini A., Rahimi A., Zare-ee A., Procedia - Social and Behavioral Sciences 28 (2011) 1029-1033.

[3] Barcelos A. M. F. (2003). Teachers' and students' beliefs within a Deweyan framework: Conflict and influence. In P.Kalaja \& A. M. F. Barcelos (Eds.), Beliefs about SLA: New research approaches (pp. 131-152). Netherlands: Kluwer Academic Publishers.

[4] Douglas Brown H. (2000). Principles of language learning and teaching. London: Longman.

[5] Byram M. (2004). Routledge encyclopedia of language teaching and learning. London: Routledge.

[6] Csizér K., Dörnyei Z. The Modern Language Journal 89 (2005) 19-36.

[7] Dörnyei Z., Ottó I., Working Papers in Applied Linguistics 4 (1998) 43-69.

[8] Gabillon Z. Journal of Language and Learning 3 (2002) 233-260.

[9] Gardner R. C. (1985). Social psychology and second language learning: Therole of attitudes and motivation. London: Edward Arnold Publishers.

[10] Heidari-Shahreza M. A. (a), International Letters of Social and Humanistic Sciences 20 (2014) 81-89.

[11] Heidari-Shahreza M. A. (b), International Letters of Social and Humanistic Sciences 23 (2014) 81-89.

[12] Horwitz E. K. (1987). Surveying student beliefs about language learning. In Rubin, Joan \& Wenden Anita (Ed).Learner strategies in language learning(pp.119-129). London: Prentice Hall. 
[13] Kennedy T. J., Nelson J. K., Odell M. R. L., Austin L. K. (2000). The FLES attitudinal inventory. Foreign Language Annuals, 33 (3), 278 -287.

[14] Kaypak E., Ortaçtepe D., System 42 (2014) 355-367.

[15] Rieger B.(2009). Exploring gender and target language effect on Hungarian EFL learners' beliefs about languagelearning. In R. Lugossy, J. Horváth, \& M. Nikolov (Eds.), UPRT 2008: Empirical studies in English applied linguistics (pp. 29-42). Pécs: Lingua Franca Csoport.

[16] Shinji Kondo D., Ying0Ling Y., ELT Journal 58 (2004) 258-265.

[17] Wenden A. L., System 27 (1999) 435-441.

[18] White C., System 27 (1999) 443-445.

[19] Williams M., Burden R. (1997). Psychology for language teachers. Cambridge: Cambridge University Press. 